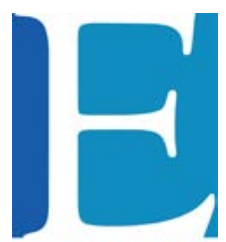

EVALUAR
2017, Vol. 17, No. 1

ISSN $1667-4545$

Recuperado de www.revistas.unc.edu.ar

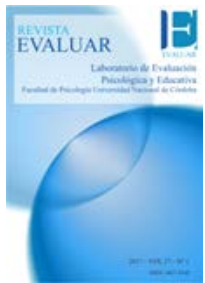

\title{
Infant Scale of Selective Attention: A Proposal to Assess Cognitive Abilities
}

\author{
Claudia Calipso Gutiérrez-Hernández*1, Thalia Harmony ${ }^{1}$, Gloria Nélida Ave- \\ cilla-Ramírez ${ }^{2}$, Ivette Barrón-Quiroz ${ }^{2}$, Verónica Guillén-Gasca², Guadalupe Tre- \\ jo-Bautista ${ }^{2}$, María Monserrat Bautista-Olvera ${ }^{2}$ \\ 1. Unidad de Investigación en Neurodesarrollo, Universidad Nacional Autónoma de México, Campus Juriquilla, México. \\ 2. Facultad de Psicología, Universidad Autónoma de Querétaro, México.
}

Introduction

Method

Results

Discussion

Conclusions

References

Recibido: 11/02/2017 Revisado: 21/03/2017 Aceptado: 05/04/2017

\begin{abstract}
The aim of this research was to test the Infant Scale of Selective Attention (EEAS, in Spanish) on healthy infants with no suspected neurological damage, in order to obtain normalcy initial parameters for the use of the instrument. The sample consisted of two hundred babies between two and eight months of age who were enrolled in the daycares of the Instituto Mexicano del Seguro Social. To obtain the normalcy initial parameters, descriptive statistics were used to calculate the mean, the standard deviation, the minimum and maximum scores, and percentiles. The EEAS allows for identification of delays in the development of the attention process by comparing an individual score to their age group in the tables. The findings of this study suggest that EEAS is a useful tool to evaluate the development of the attention process during infancy.
\end{abstract}

Keywords: Infant development, cognition, selective attention, assessment scale

\section{Resumen}

El objetivo de la presente investigación fue probar la Escala de Evaluación de la Atención Selectiva (EEAS) en lactantes sanos sin sospecha de daño neurológico, con la finalidad de obtener parámetros iniciales de normalidad para el uso del instrumento. La muestra estuvo integrada por 200 lactantes con un rango de edad entre dos y ocho meses, adscritos al sistema de guarderías del Instituto Mexicano del Seguro Social. Para obtener los parámetros iniciales de normalidad se utilizó estadística descriptiva para calcular la media, la desviación estándar, puntajes máximos y mínimos y percentiles. La EEAS permite identificar retrasos en el desarrollo del proceso de atención al comparar un puntaje individual contra su grupo de edad en tablas. Los hallazgos de este estudio sugieren que la EEAS es un instrumento útil para evaluar el desarrollo del proceso de atención durante la infancia.

Palabras clave: Desarrollo infantil, cognición, atención selectiva, escala de evaluación

\footnotetext{
*Corresponding author: Claudia Calipso Gutiérrez-Hernández, Instituto de Neurobiología, UNAM. Campus Juriquilla, Blvd. Juriquilla 3001, Juriquilla, Querétaro, 76230, México. Tel. (01442) 1926101. calipso_cl@hotmail.com

How to cite this article: Gutiérrez-Hernández, C. C., Harmony, T., Avecilla-Ramírez, G. N., Barrón-Quiroz, I., Guillén-Gasca, V., Trejo-Bautista, G., Bautista-Olvera, M. M. (2017). Infant Scale of Selective Attention: A proposal to assess cognitive abilities. Revista Evaluar, 17(1), 94-106. Recuperado de https://revistas.unc.edu.ar/index.php/revaluar

Aknowledgements: The authors want to thank the Instituto Mexicano del Seguro Social for their invaluable collaboration. We would also like to thank Hector Belmont Tamayo and nurse Delia Evelia Figueroa for their technical support. This project was partially supported by Grant number IN220110 from UNAM's Direction General of Academic Personnel Issues (in Spanish: Dirección General de Asuntos del Personal Académico de la 


\section{Introduction}

Attention is a subjectively evident cognitive experience, but it is difficult to characterize (Richards, Reynolds, \& Courage, 2010). The attentional process is involved in determining which internal and external stimuli are selected for subsequent processing (Reynolds \& Romano, 2016). Studying the development of attentional processes is complicated due to the difficulty in separating attention from encoding, memory, decision making, and response systems (Gomes, Wolfson, \& Halperin, 2007). For instance, orientation of attention determines which information is selected for learning and memory (Ross-Sheehy, Oakes, \& Luck, 2011; Wu, Gopnik, Richardson, \& Kirkham, 2011); and orienting toward target stimuli while simultaneously suppressing distraction affects how well information is learned and retrieved (Markant \& Amso, 2013, 2014, 2016).

Selective attention involves the selection of a specific object or spatial location as the focus of attention. This process is influenced by both external and internal factors, such as individual interests and motives, and personal cognitive strategies to pay attention to the stimuli (Gomes, Molholm, Christodoulou, Ritter, \& Cowan, 2000; Reynolds, 2015). Extensive research has established that selective attention involves enhanced processing of the location where attention is focused and the simultaneous suppression of distracting factors (Carrasco, 2014).

The systems that are related to attention are the alert, orienting and executive networks (Petersen \& Posner, 2012; Posner \& Petersen, 1990). These components reflect the general state of a subject regarding information processing and his or her abilities to orient toward, select, switch between, and maintain the source of information (Kushnerenko, Van den Bergh, \& Winkler, 2013). The development of infant attention is thought to be closely related to changes in the neural systems underlying orienting attention control (Richards et al., 2010; Posner, Rothbart, Sheese, \& Voelker, 2014).

Ontogenetically, it is possible for newborns to reach an alert state, but this is not a frequent or extended occurrence during the first month of life. During the postnatal period, from 4 to 8 or 10 weeks, alertness is reached more frequently and for longer periods. The components of the spatial orienting system seem to have somewhat different developmental paths, but they all appear to be fairly well established by the age of 6 months. Smooth pursuit, reflexive saccades and inhibition of return can be elicited in newborns, but they progress significantly throughout the first half-year of age. Disengagement of attention is also present in a rudimentary form very early in life, but it appears to show considerable improvement between 2 and 4 months of age. The fundamental functions that relate to object perception (detection of color and shape) are probably present in some rudimentary form at birth but, as with spatial orienting, substantial changes occur during the interval between 2 to 5 or 6 months of age (Salapatek, Aslin, Simonson, \& Pulos, 1980; Colombo, 2001). Infants are most commonly assessed according to spontaneous motor and psychophysiological responses: e.g. localized head turning (Clarkson \& Berg, 1983; Morrongiello, Fenwick, Hillier, \& Chance, 1994), or changes in the heart rate (Richards \& Casey, 1991). Sometimes parameters such as behavioral inhibition, motor quieting, and eye movement are also used in assessing responsiveness in newborns (Gomes et al., 2000). Orienting responses to various sounds (a bell, a rattle, human voice) are often used by pediatricians as part of clinical assessments in newborns.

Attention in infants has been studied using a variety of behavioral procedures. There are different neurodevelopmental assessments and scales for infants, but they do not focus directly on attention. Therefore, it was of great impor- 
tance for this project to develop instruments for the early detection of attention delay in infants during the first months of life.

In 2007, the Infant Scale of Selective Attention (EEAS) was published in Spanish to further the assessment of attention development. The EEAS was originally designed to measure the attention process development in a population specially at risk (premature infants with brain damage). Now, there is an interest to test the scale on healthy infants.

The aim of this study was to test the instrument on infants with no history of brain damage, in order to obtain normalcy initial parameters for the use of the scale.

\section{Method}

Participants

This study was conducted in collaboration with the Instituto Mexicano del Seguro Social (IMSS). This Institute is responsible for providing public assistance and health services in Mexico, including services of childcare exclusive for working mothers.

As part of the admission guidelines to the daycare centers, it is essential that every child be given a complete medical examination at their corresponding Family Medicine Unit (UMF) that includes assessment of prenatal risk factors, pathological records, physical and neurological examination, among others (Instituto Mexicano del Seguro Social [IMSS], 2015). Thus, only participants with no history of risk of neurological damage and with no pathologies or disability recorded in their clinical history were included in the study.

The sample was integrated considering the following inclusion criteria: absence of prenatal and/or perinatal complications, birth weight between 2,500 and 3,800 grams and gestational age between 38 and 42 weeks. Two hundred healthy infants ( 89 males and 111 females) between 1 to 8 months of age were included. All participants were Mexican children of working mothers who attended daycare centers for a daily average of 8 hours. Some socioeconomic characteristics of mothers of infants were as follows: all were Spanish speakers; $40 \%$ of the mothers had a university degree; $31 \%$ only finished high school (twelve years of scholar instruction); $18 \%$ only finished secondary school (nine years of scholar instruction); $8 \%$ had some kind of technical training; only $3 \%$ had a postgraduate degree. In terms of age range, it was distributed as follows: $56 \%$ of the mothers were between 20 to 30 years old; $40 \%$ were 31 to 40 years old; only $4 \%$ were younger than 20 years old. Regarding income levels, they were as follows: $38 \%$ of the families reported a monthly family income of less than \$5,000 Mexican pesos; $20 \%$, from $\$ 5,000$ to $\$ 10,000 \mathrm{MXN}$; $18 \%$, from $\$ 10,000$ to $\$ 15,000 \mathrm{MXN} ; 9 \%$, from $\$ 15,000$ to $20,000 \mathrm{MXN} ; 8 \%$, from $\$ 20,00$ to $\$ 25,000 \mathrm{MXN}$; only $5 \%$ of the families reported an income higher to $\$ 25,000$ Mexican pesos.

Additionally, an independent sample of 35 participants with the same characteristics as the previous one was integrated to confirm the reliability of the instrument. Participation in the study was agreed upon through a consent form.

\section{Instrument}

The Infant Scale of Selective Attention is known in Spanish as the Escala de Evaluación de la Atención Selectiva (EEAS; Gutiérrez-Hernández \& Harmony, 2007). In broad terms, the EEAS continuously assesses the development of the attention process in infants from 1 to 8 months of age. The creation of the EEAS was supported by an extensive review of literature on developmental theories and precedent scales designed to assess child development, such as the Bayley Scales of Infant Tooddler Develop- 
ment (BSID-III; Bayley, 2006); the Guía Portage de Educación Preescolar; (GPEP; Bluma, Shearer, Forman, \& Hilliard, 1995); the Escala de Matas (EM; Matas, Maureen de Mulvey, Paone, Segura, \& Tapia, 1997); and the Valoración Neuroconductual del Desarrollo del Lactante (VANEDELA; Sánchez-Pérez, Benavides-González, \& Mandujano-Valdés, 2007).

The instrument has 46 items in total and consists of two subscales:

1. Visual Scale: It consists of 32 items and it is designed to evaluate the baby's ability to detect, locate, track, and respond selectively to visual stimuli (cards, mirror, ring, cubes, ball).

2. Auditory Scale: It consists of 14 items and it is designed to evaluate the baby's ability to detect, locate, track, and respond selectively to auditory stimuli (voice, bell, rattle).

\section{Test administration}

The evaluation was performed individually on each participant in the nurse's office of the daycares (thought to be a suitable place because it was quiet, free of distractions, ventilated, and had good lighting) in presence of their caregivers. The EEAS was applied by two psychologists who were trained in neurodevelopment assessment to control the bias in the rating of responses. All participants were evaluated between 9:00 AM and 11:00 AM. Those participants with signs of irritability, somnolence, crying, discomfort or poor collaboration were excluded from the study. The execution of the EEAS was brief; it lasted about 20 minutes.

In order to carry out the experiment more efficiently, some modifications were made, the most important being that in the Spanish version 4 categories to rate the responses were used $(0=$ no response, $1=$ emerging response, $2=$ in progress, and $3=$ satisfactory response). Due to the difficulty in discerning between categories 1 and 2 , it was decided to consider both categories as one. Therefore, this study used the following criteria: $0=$ no response, $1=$ in process, and $2=$ satisfactory response. In addition, the criterion for stopping the administration of test was reduced from 4 to 3 consecutive scores of 0 .

Steps to obtain raw scores. The information was recorded in the summary page (demographic information and chronological age in months).

1. The test was initiated with item number 1 for both subscales.

2. The infant's score must be registered in the column that corresponds to the infant's age.

3. The infant's performance was scored using these criteria: 2 , if the child responded or performed satisfactorily; 1 , if the child's response was in process; 0 , if the child did not respond. The criteria for scoring the responses of infants are in the following guide:

\section{Visual scale:}

A) Items 1, 3, 4, 5, 6, 8, 9, 10, 17 and 22 evaluate the ability to detect and observe visual stimuli targeting them selectively. Grant 2 points if the child momentarily (for at least 3 seconds) fixes his or her gaze on the stimuli (an adult's face, cards, a mirror, a ring, a small cube, chips). Grant 1 point if an unconvincing attempt to respond is noticed. The absence of response is scored with 0 .

B) Items 2, 7, 11, 12, 13, 14, 15, 16 and 24 evaluate the infant's ability to locate and follow visual stimuli with selective orienting response. Grant 2 points if the child's eyes follow the moving stimuli. For items 15 and 16, grant the point if the child turns his or her head or flexes his or her neck to follow the card. Grant 1 point if an unconvincing attempt to respond is noticed. The absence of response is scored with 0 .

C) Items $18,19,20,21,23,25,26,27,28$, $29,30,31$ and 32 assess the infant's ability to detect, locate and follow objects with coordinated eye-hand movements. Grant 2 points if the child responds with voluntary and coordinated 
movements, for example, trying to reach the mirror with his or her hands, grasping or manipulating objects. Grant 1 point if an unconvincing attempt to respond is noticed. The absence of response is scored with 0 .

\section{Auditory scale:}

A) Items 1, 2, 3, 4 and 7 assess the infant's ability to detect auditory stimuli and orient the attention selectively. Grant 2 points if the child clearly responds to the sounds (voice, bell, or rattle) by turning his or her eyes, vocalizing, changing activity level (increasing or decreasing), changing facial expression, etc. Grant 1 point if an unconvincing attempt to respond is noticed. Do not grant any points if the child shows a response of 5 seconds or more after exposure to the stimuli, for this might not be related to the sound used in the test.

B) Items 5, 6, 8, 9, 10, 11 and 12 evaluate the ability to orient, locate and follow auditory stimuli with responses accompanied by gross voluntary movements. Grant 2 points if the infant clearly responds with the required movement (turning his or her head, flexing the neck, watching a rattle while flapping his or her hands, etc.). Grant 1 point if an unconvincing attempt to respond is noticed. The absence of response is scored with 0 .

C) Item 13 requires both sitting posture control and eye searching movements in relation to the place where the sound occurs. Grant 2 points only if the child's response meets both criteria. Grant 1 point if the response includes only one of the two criteria, and 0 points if there is no response.

D) Item 14 is related to the attempts at using language. Grant 2 points if the child imitates adult vocalization. Grant 1 point if there is doubt as to whether the vocalizations uttered by the child are related to the imitation of adult vocalizations, and 0 points if there is no response.
4. The test was stopped after 3 consecutive scores of 0 .

5. The raw scores (visual, auditory and total) were obtained.

\section{Data analysis}

The results were analyzed using SPSS version 17.0 (IBM, 2009). To obtain the normalcy initial parameters, descriptive statistics were used to calculate frequency distribution, mean, standard deviation, minimum and maximum scores, and the percentiles for visual and auditory scales, as well as the total scores. The coefficients of reliability were obtained through the Pearson's Correlation.

\section{Results}

Normalcy Initial Parameters

Using the data of our sample, consisting of 200 subjects, normalcy initial parameters were obtained to measure the development of the attention process quantitatively and qualitatively in healthy babies. Tables 1, 2 and 3 show these results from 1 to 8 months of age for the visual, auditory scales and total score. The columns show the infant's age in months. For example, for a 2-month-old $(2 \mathrm{~m})$. Percentiles are shown on the lines. If the scores were between the 25 th and 75th percentiles, the attentional development was classified as Normal. If the score was below the 25th percentile, the attention development was considered Deficient. Finally, if the score was above the 75th percentile, the attention development was classified as Accelerated Performance. 
Table 1

Normalcy Initial Parameters (visual scale).

\begin{tabular}{|c|c|c|c|c|c|c|c|c|c|}
\hline \multicolumn{10}{|c|}{ Visual scale } \\
\hline & & $1 \mathrm{~m}$ & $2 \mathrm{~m}$ & $3 \mathrm{~m}$ & $4 m$ & $5 \mathrm{~m}$ & $6 \mathrm{~m}$ & $7 \mathrm{~m}$ & $8 m$ \\
\hline $\mathrm{N}$ & & 4 & 19 & 29 & 33 & 38 & 45 & 23 & 9 \\
\hline Mean & & 12.8 & 15.8 & 23.8 & 35.0 & 41.6 & 49.8 & 55.6 & 57.7 \\
\hline S.D. & & 5.6 & 6.4 & 7.0 & 10.1 & 12.3 & 12.9 & 10.0 & 10.8 \\
\hline Minimum & & 7 & 8 & 8 & 18 & 17 & 17 & 27 & 35 \\
\hline Maximum & & 20 & 28 & 40 & 54 & 63 & 64 & 64 & 64 \\
\hline \multicolumn{10}{|l|}{ Percentiles } \\
\hline \multirow{2}{*}{ Deficient } & 10 & 7 & 8 & 15 & 19 & 24 & 30 & 38 & 35 \\
\hline & 20 & 7 & 9 & 18 & 24 & 30 & 38 & 47 & 43 \\
\hline \multirow{7}{*}{ Normal } & 25 & 8 & 10 & 20 & 27 & 33 & 42 & 52 & 53 \\
\hline & 30 & 9 & 11 & 21 & 29 & 34 & 45 & 53 & 62 \\
\hline & 40 & 10 & 13 & 22 & 32 & 40 & 50 & 57 & 63 \\
\hline & 50 & 12 & 15 & 24 & 36 & 41 & 54 & 60 & 63 \\
\hline & 60 & 14 & 16 & 26 & 39 & 46 & 55 & 61 & 63 \\
\hline & 70 & 17 & 21 & 28 & 43 & 52 & 59 & 62 & 63 \\
\hline & 75 & 19 & 21 & 29 & 44 & 53 & 62 & 63 & 63 \\
\hline \multirow{3}{*}{$\begin{array}{l}\text { Accelerated } \\
\text { Performance }\end{array}$} & 80 & 20 & 23 & 29 & 44 & 54 & 62 & 64 & 63 \\
\hline & 90 & 20 & 25 & 33 & 48 & 56 & 63 & 64 & 64 \\
\hline & 100 & 20 & 28 & 40 & 54 & 63 & 64 & 64 & 64 \\
\hline
\end{tabular}

Table 2

Normalcy Initial Parameters (auditory scale).

\section{Auditory scale}

\begin{tabular}{lcccccccc} 
& $\mathbf{1 m}$ & $\mathbf{2 m}$ & $\mathbf{3 m}$ & $\mathbf{4 m}$ & $\mathbf{5 m}$ & $\mathbf{6 m}$ & $\mathbf{7 m}$ & $\mathbf{8 m}$ \\
\hline $\mathrm{N}$ & 4 & 19 & 29 & 33 & 38 & 45 & 23 & 9 \\
Mean & 7.5 & 8.4 & 13.0 & 19.6 & 21.9 & 24.9 & 26.3 & 25.6 \\
S.D. & 7.0 & 4.0 & 5.5 & 6.0 & 5.9 & 3.8 & 2.3 & 3.3 \\
Minimum & 4 & 1 & 2 & 4 & 4 & 9 & 20 & 19 \\
Maximum & 18 & 18 & 22 & 28 & 28 & 28 & 28 & 28
\end{tabular}

Percentiles

$\begin{array}{llllllllll} & 10 & 4 & 4 & 4 & 10 & 13 & 20 & 22 & 19 \\ \text { Deficient } & 20 & 4 & 4 & 10 & 15 & 17 & 23 & 25 & 21\end{array}$




\begin{tabular}{|c|c|c|c|c|c|c|c|c|c|}
\hline \multicolumn{10}{|c|}{ Auditory scale } \\
\hline & & $1 \mathrm{~m}$ & $2 \mathrm{~m}$ & $3 \mathrm{~m}$ & $4 m$ & $5 \mathrm{~m}$ & $6 \mathrm{~m}$ & $7 \mathrm{~m}$ & $8 m$ \\
\hline \multirow{7}{*}{ Normal } & 25 & 4 & 6 & 11 & 16 & 18 & 23 & 25 & 24 \\
\hline & 30 & 4 & 6 & 11 & 17 & 19 & 24 & 25 & 26 \\
\hline & 40 & 4 & 7 & 12 & 20 & 23 & 26 & 26 & 26 \\
\hline & 50 & 4 & 8 & 13 & 21 & 24 & 26 & 28 & 26 \\
\hline & 60 & 4 & 9 & 14 & 22 & 25 & 26 & 28 & 28 \\
\hline & 70 & 11 & 10 & 16 & 24 & 26 & 28 & 28 & 28 \\
\hline & 75 & 15 & 11 & 18 & 24 & 26 & 28 & 28 & 28 \\
\hline \multirow{3}{*}{$\begin{array}{l}\text { Accelerated } \\
\text { Performance }\end{array}$} & 80 & 18 & 12 & 18 & 24 & 26 & 28 & 28 & 28 \\
\hline & 90 & 18 & 14 & 20 & 27 & 28 & 28 & 28 & 28 \\
\hline & 100 & 18 & 18 & 22 & 28 & 28 & 28 & 28 & 28 \\
\hline
\end{tabular}

Table 3

Normalcy Initial Parameters (total score).

\section{Total score}

\begin{tabular}{|c|c|c|c|c|c|c|c|c|c|}
\hline & & $1 \mathrm{~m}$ & $2 m$ & $3 m$ & $4 m$ & $5 \mathrm{~m}$ & $6 \mathrm{~m}$ & $7 \mathrm{~m}$ & $8 m$ \\
\hline $\mathrm{N}$ & & 4 & 19 & 29 & 33 & 38 & 45 & 23 & 9 \\
\hline Mean & & 20.3 & 24.3 & 36.8 & 54.6 & 63.5 & 74.7 & 81.9 & 83.2 \\
\hline S.D. & & 9.6 & 9.3 & 10.1 & 14.4 & 16.9 & 15.1 & 11.8 & 13.8 \\
\hline Minimum & & 11 & 12 & 20 & 27 & 21 & 40 & 47 & 56 \\
\hline Maximum & & 32 & 46 & 62 & 78 & 89 & 92 & 92 & 91 \\
\hline \multicolumn{10}{|l|}{ Percentiles } \\
\hline \multirow[b]{2}{*}{ Deficient } & 10 & 11 & 13 & 22 & 32 & 38 & 47 & 61 & 56 \\
\hline & 20 & 11 & 16 & 29 & 38 & 48 & 61 & 73 & 62 \\
\hline \multirow{7}{*}{ Normal } & 25 & 12 & 16 & 31 & 44 & 49 & 67 & 77 & 76 \\
\hline & 30 & 13 & 17 & 31 & 49 & 52 & 71 & 80 & 89 \\
\hline & 40 & 14 & 19 & 33 & 52 & 60 & 76 & 84 & 89 \\
\hline & 50 & 19 & 24 & 36 & 55 & 66 & 79 & 86 & 90 \\
\hline & 60 & 24 & 26 & 39 & 62 & 70 & 82 & 87 & 90 \\
\hline & 70 & 28 & 31 & 43 & 63 & 79 & 85 & 90 & 91 \\
\hline & 75 & 30 & 31 & 44 & 67 & 79 & 88 & 90 & 91 \\
\hline \multirow{3}{*}{$\begin{array}{l}\text { Accelerated } \\
\text { Performance }\end{array}$} & 80 & 32 & 33 & 44 & 70 & 80 & 89 & 91 & 91 \\
\hline & 90 & 32 & 37 & 54 & 73 & 83 & 91 & 92 & 91 \\
\hline & 100 & 32 & 46 & 62 & 78 & 89 & 92 & 92 & 91 \\
\hline
\end{tabular}


Reliability Process for the EEAS

After completing the analysis of the sample's data, the instrument was tested once again on a new independent sample consisting of 35 subjects with the same characteristics as the previous one (healthy infants with not suspected risk factors of brain damage) to verify the reliability of the EEAS. This data was correlated with that of 35 subjects randomly chosen from the previous sample. Reliability coefficients were obtained using the Person's Correlation. The coefficients were .985 for the visual scale, .846 for the auditory scale, and .974 for the total score.

\section{Distribution of frequencies}

The distribution of frequencies is showed in the figures 1 and 2. The participants were grouped according to their age, but the graphics only show the total scores at 2 (Figure 1) and 7 months (Figure 2).

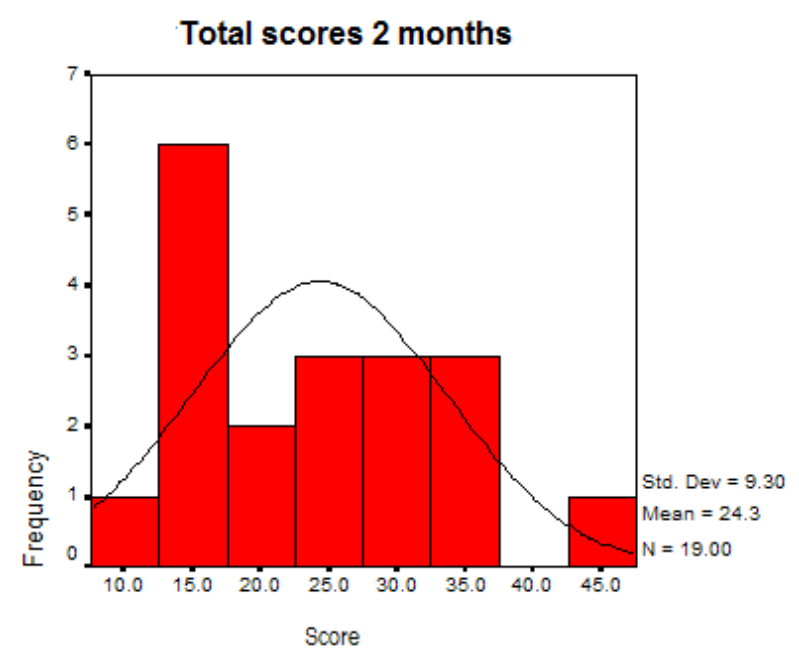

Figure 1

Total scores for 2-month-olds.

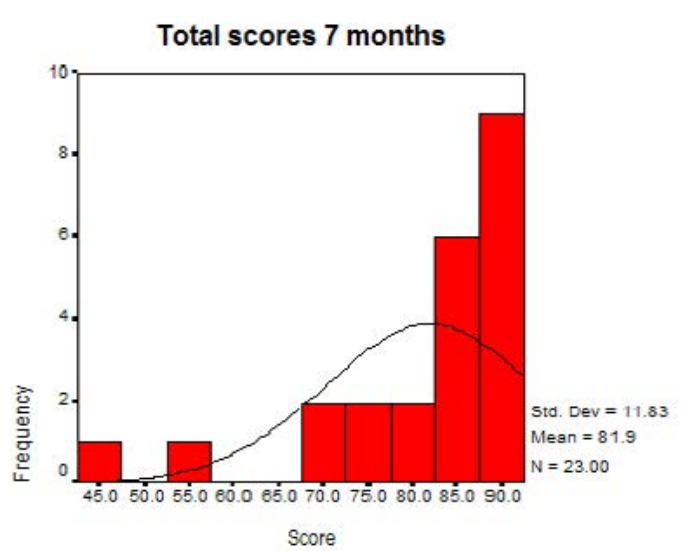

Figure 2

Total scores for 7-month-olds

\section{Discussion}

Many scales have been designed with the purpose of measuring both child's normal development or alterations, such as motor retardation, disruptive behavior, social dysfunction and cognitive delay. Although it is well known that the attentional process is involved in determining which internal and external stimuli are selected for subsequent processing (Reynolds \& Romano, 2016), no scale has been proposed to measure this cognitive process specifically during infancy.

For this study, the EEAS was applied to healthy infants enrolled in the daycares of IMSS who showed no risk factors of brain damage. The institute's operating guidelines permited to have control over some application conditions, such as all children having a complete medical examination upon admission. Feeding, rest and exposure to stimulation were regulated similarly for all participants in the daycare. However, variables related to sociocultural or family aspects, such as mother-child interaction, could not be controlled.

The participants were grouped according to their age, but not all the groups were integrated by an equal number of subjects. For example, to include more one-month-old children 
was very difficult, for the infants are enrolled in the nursery only after their 45th day of birth, and the admission process is long; thus, groups of children older than two months were bigger.

Likewise, the subjects' scores are not homogeneous even when they belong to the same age group. This variability could be attributed to multiple factors that may or may not be related with the functionality of the attention system. As mentioned before, attention is a difficult process to characterize and separate from other cognitive domains, such as memory, learning or efferent mechanisms responsible for the emission of responses in the presence of a stimulus (Reynolds, 2015). As with other neurodevelopmental scales, sometimes states of irritability, drowsiness, apathy, and inadequate application conditions could affect the results. In such a case, re-executing the test is recommended.

On the other hand, frequencies of the scores appear to be distributed normally during the first months. This can be seen in the total scores of the Figure 1 for the 2-month-olds. In contrast, the distribution of scores for the 7-month-olds is asymmetric with a tendency towards high scores (Figure 2). The fact that during the first months of age the distribution tends to be normal could be attributed to the phylogenetic development of the attention process for humans. Humans are born equipped with mechanisms that allow them to determine which environmental stimuli represent a threat and which guarantee their survival. It is possible that during the first months of life these mechanisms are present primitively in all subjects, but when the stimuli that demand attention become more complex and require simultaneous activation of other neural networks, evidence of an immature attentive system appears.

Finally, the tables of percentiles herein provide an initial approximation to behavioral measure of visual and auditory attention during the first months of life. Percentiles as a statistical measure identify when a value is below or above the norm, in this case, regarding age group. Although the sample was small, these results are useful to observe the ontogenetic development of the attention process.

\section{Conclusions}

The EEAS provides the possibility of measuring the development of attention during the first months of life.

The EEAS permits to detect delays in the development of the visual and auditory selective attention and monitore this process monthly.

Although the data presented is reliable, it is believed that further testing of the instrument with a larger number of subjects of 1 to 8 months of age is necessary to prevent false positives and to be able to generalize the results.

\section{References}

Bayley, N. (2006). Bayley Scales of Infant and Toddler Development ${ }^{\circledR}$ (3rd ed.). San Antonio: Psychological Corporation. Retrieved from http://www.pearsonclinical.com/

Bluma, M., Shearer, S., Forman, A., \& Hilliard, J. (1995). Portage Guide to Early Education, Manual and Checklist. Revised Edition and Guia Portage de Educacion Preescolar. Manual y Lista de Objetivos. Edicion Revisada. Cooperative Educational Service Agency.

Carrasco, M. (2014). Spatial Covert Attention. Oxford Handbooks Online. doi: 10.1093/oxford$\mathrm{hb} / 9780199675111.013 .004$

Clarkson, M. G., \& Berg, W. K. (1983). Cardiac orienting and vowel discrimination in newborns: Crucial stimulus parameters. Child Development, 54(1), 162-71. Retrieved from http://www.ncbi.nlm.nih. gov/pubmed/6831983

Colombo, J. (2001). The development of visual attention in infancy. Annual Review of Psychology, 52(1), 337-367. doi: 10.1146/annurev.psych.52.1.337 
Gomes, H., Molholm, S., Christodoulou, C., Ritter, W., \& Cowan, N. (2000). The development of auditory attention in children. Frontiers in Bioscience: A Journal and Virtual Library, 5. Retrieved from http://www.ncbi.nlm.nih.gov/pubmed/10702373

Gomes, H., Wolfson, V., \& Halperin, J. M. (2007). Is there a selective relationship between language functioning and auditory attention in children? Journal of Clinical and Experimental Neuropsychology, 29(6), 660-668. doi: 10.1080/13803390600920455

Gutiérrez-Hernández, C., \& Harmony, T. (2007). Evaluación conductual de la atención selectiva visual y auditiva en lactantes con factores perinatales de riesgo de daño cerebral. Revista de Neuropsicología, 2(1), 3-9. Retrieved from http://www.imbiomed. com. $\mathrm{mx} / 1 / 1 /$ articulos.php? method=showDetail\&id_articulo $=49076 \&$ id_seccion $=2642 \& i d$ ejemplar $=4976 \&$ id_revista $=159$

IBM Corporation. (2009). IBM SPSS Statistics (17).

Instituto Mexicano del Seguro Social. (2015). Procedimiento para la inscripción y registro de asistencia de las niñas y niños en las guarderías de prestación indirecta. Retrieved from http://siag. imss.gob.mx/instalacionsiag/Guarderias/Normas/ Portal/Pocedimiento.PI.PDF

Kushnerenko, E. V., Van den Bergh, B. R. H., \& Winkler, I. (2013). Separating acoustic deviance from novelty during the first year of life: A review of event-related potential evidence. Frontiers in Psychology, 4, 595. doi: 10.3389/fpsyg.2013.00595

Markant, J., \& Amso, D. (2013). Selective memories: Infants' encoding is enhanced in selection via suppression. Developmental Science, 16, 926-940. doi: 10.1111/desc. 12084

Markant, J., \& Amso, D. (2014). Leveling the playing field: Attention mitigates the effects of intelligence on memory. Cognition, 131, 195-204. doi: 10.1016/j.cognition.2014.01.006

Markant, J., \& Amso, D. (2016). The development of selective attention orienting is an agent of change in learning and memory efficacy. Infancy, 21(2), 154176. doi: 10.1111/infa. 12100

Matas, S., Maureen de Mulvey, M., Paone, S., Segura, E., \& Tapia, L. (1997). Estimulación temprana de 0 a
36 meses (5th ed.). Buenos Aires: Lumen-Hvmanitas.

Morrongiello, B. A., Fenwick, K. D., Hillier, L., \& Chance, G. (1994). Sound localization in newborn human infants. Developmental Psychobiology, 27(8), 519-538. doi: 10.1002/dev.420270805

Petersen, S., \& Posner, M. (2012). The attention system of the human brain: 20 years after. Annual Review of Neuroscience, 35(1), 73-89. doi: 10.1146/annurev-neuro-062111-150525

Posner, M. I., \& Petersen, S. E. (1990). The attention system of the human brain. Annual Review of Neuroscience, 13, 25-42. Retrieved from http://cns-web. bu.edu/Profiles/Mingolla.html/cnsftp/cn730-2007pdf/posner_petersen90.pdf

Posner, M. I., Rothbart, M. K., Sheese, B. E., \& Voelker, P. (2014). Developing attention: Behavioral and brain mechanisms. Advances in Neuroscience (Hindawi), 2014, 1-9. doi: 10.1155/2014/405094

Reynolds, G. D. (2015). Infant visual attention and object recognition. Behavioural Brain Research, 285, 3443. doi: 10.1016/j.bbr.2015.01.015

Reynolds, G. D., \& Romano, A. C. (2016). The development of attention systems and working memory in infancy. Frontiers in Systems Neuroscience, 10, 15. doi: 10.3389/fnsys.2016.00015

Richards, J. E., \& Casey, B. J. (1991). Heart rate variability during attention phases in young infants. Psychophysiology, 28(1), 43-53. Retrieved from http:// www.ncbi.nlm.nih.gov/pubmed/1886963

Richards, J. E., Reynolds, G. D., \& Courage, M. L. (2010). The neural bases of infant attention. Current Directions in Psychological Science, 19(1), 41-46. doi: 10.1177/0963721409360003

Ross-Sheehy, S., Oakes, L. M., \& Luck, S. J. (2011). Exogenous attention influences visual short-term memory in infants. Developmental Science, 14(3), 490-501. doi: 10.1111/j.1467-7687.2010.00992.x

Salapatek, P., Aslin, R. N., Simonson, J., \& Pulos, E. (1980). Infant saccadic eye movements to visible and previously visible targets. Child Development, 51(4), 1090. doi.: 10.2307/1129548

Sánchez-Pérez, M., Benavides-González, H., \& Mandujano-Valdés, M. (2007). Valoración neuroconduc- 
tual del desarrollo del lactante (VANEDELA) :

Manual. UAM, Unidad Xochimilco, División de Ciencias Biológicas y de la Salud. Retrieved from http://www.dicyt.com/publicaciones/valoraci-n-neuroconductual-de-desarrollo-del-lactante-vanedela

Wu, R., Gopnik, A., Richardson, D. C., \& Kirkham, N.

Z. (2011). Infants learn about objects from statistics and people. Developmental Psychology, 47(5), 1220-1229. doi: 10.1037/a0024023

\section{Appendix 1. Summary page}

\section{Infant Scale of Selective Attention}

Name

Gestational age
Date of birth

Date of testing

\begin{tabular}{|c|c|c|c|c|c|c|c|}
\hline & $\begin{array}{l}\text { Raw Score } \\
\text { Visual Scale }\end{array}$ & $\mathrm{P}$ & $\begin{array}{c}\text { Raw Score Au- } \\
\text { ditory Scale }\end{array}$ & $\mathrm{P}$ & Classification & $\mathrm{P}$ & Classification \\
\hline \multicolumn{8}{|l|}{1 Month } \\
\hline \multicolumn{8}{|l|}{2 Months } \\
\hline \multicolumn{8}{|l|}{3 Months } \\
\hline \multicolumn{8}{|l|}{4 Months } \\
\hline \multicolumn{8}{|l|}{5 Months } \\
\hline \multicolumn{8}{|l|}{6 Months } \\
\hline \multicolumn{8}{|l|}{7 Months } \\
\hline 8 Months & & & & & & & \\
\hline
\end{tabular}

Note. $\mathrm{P}=$ Percentile

\section{Appendix 2. Visual scale}

\begin{tabular}{|c|c|c|c|c|c|c|c|c|c|}
\hline & \multirow{2}{*}{ Visual Scale } & \multicolumn{7}{|c|}{ Age (Months) } & \multirow[t]{2}{*}{ Notes } \\
\hline & & 2 & 3 & 4 & 5 & 6 & 7 & 8 & \\
\hline 1 & Visual contact with an adult & & & & & & & & \\
\hline 2 & Visual contact with a moving adult & & & & & & & & \\
\hline 3 & $\begin{array}{l}\text { Contemplating a card ( } 25-30 \text { centimeters at the } \\
\text { midline) }\end{array}$ & & & & & & & & \\
\hline 4 & Contemplating a card ( 90 centimeters at the midline) & & & & & & & & \\
\hline 5 & Looking a card at their right & & & & & & & & \\
\hline 6 & Looking a card at their left & & & & & & & & \\
\hline
\end{tabular}




\begin{tabular}{|c|c|c|c|c|c|c|c|c|c|}
\hline \multirow{2}{*}{\multicolumn{2}{|c|}{ Visual Scale }} & \multicolumn{7}{|c|}{ Age (Months) } & \multirow[t]{2}{*}{ Notes } \\
\hline & & 2 & 3 & 4 & 5 & 6 & 7 & 8 & \\
\hline 7 & $\begin{array}{l}\text { Eyes following a moving card from right to left and } \\
\text { vice versa }\end{array}$ & & & & & & & & \\
\hline 8 & Looking at a ring for 3 seconds (at the midline) & & & & & & & & \\
\hline 9 & $\begin{array}{l}\text { Seeing himself or herself in a mirror ( } 20 \text { centimeters at } \\
\text { the midline). }\end{array}$ & & & & & & & & \\
\hline 10 & Eyes fixating on one of two different cards & & & & & & & & \\
\hline 11 & $\begin{array}{l}\text { Tracking the movement of cards increasing in distance } \\
(45-90 \mathrm{~cm})\end{array}$ & & & & & & & & \\
\hline 12 & Eyes following a ring (horizontal path) & & & & & & & & \\
\hline 13 & Eyes following a ring (vertical excursion path) & & & & & & & & \\
\hline 14 & Eyes following a ring (circular path) & & & & & & & & \\
\hline 15 & $\begin{array}{l}\text { Tracking the movement of a card from right to left } \\
\text { (full turn head) }\end{array}$ & & & & & & & & \\
\hline 16 & $\begin{array}{l}\text { Tracking the movement of a card up-down (fully } \\
\text { flexing and extending the neck) }\end{array}$ & & & & & & & & \\
\hline 17 & Observation of a small cube for 3 seconds. & & & & & & & & \\
\hline 18 & Observing, grasping and manipulating a ring & & & & & & & & \\
\hline 19 & Observing, grasping and manipulating a swinging ring & & & & & & & & \\
\hline 20 & Visually tracking and grasping a rod & & & & & & & & \\
\hline 21 & $\begin{array}{l}\text { Eyes following a ball rolling across a table, trying to } \\
\text { take it }\end{array}$ & & & & & & & & \\
\hline 22 & Looking at a small plastic piece. & & & & & & & & \\
\hline 23 & $\begin{array}{l}\text { Observing and aproaching to his or her image in the } \\
\text { mirror }\end{array}$ & & & & & & & & \\
\hline 24 & Following the fall of a balloon & & & & & & & & \\
\hline 25 & Reaching cubes placed on a table & & & & & & & & \\
\hline 26 & Finding a hidden ball & & & & & & & & \\
\hline 27 & Observing and manipulating a rope attached to-a ring & & & & & & & & \\
\hline 28 & Searching hidden familiar face- & & & & & & & & \\
\hline 29 & Smiling at and touching a mirror & & & & & & & & \\
\hline 30 & Using eye-hand coordination to take a sugar pellet & & & & & & & & \\
\hline 31 & Taking objects and hitting-a table with them & & & & & & & & \\
\hline 32 & Retaining two cubes simultaneously for 3 seconds & & & & & & & & \\
\hline
\end{tabular}




\section{Appendix 3. Auditory scale}

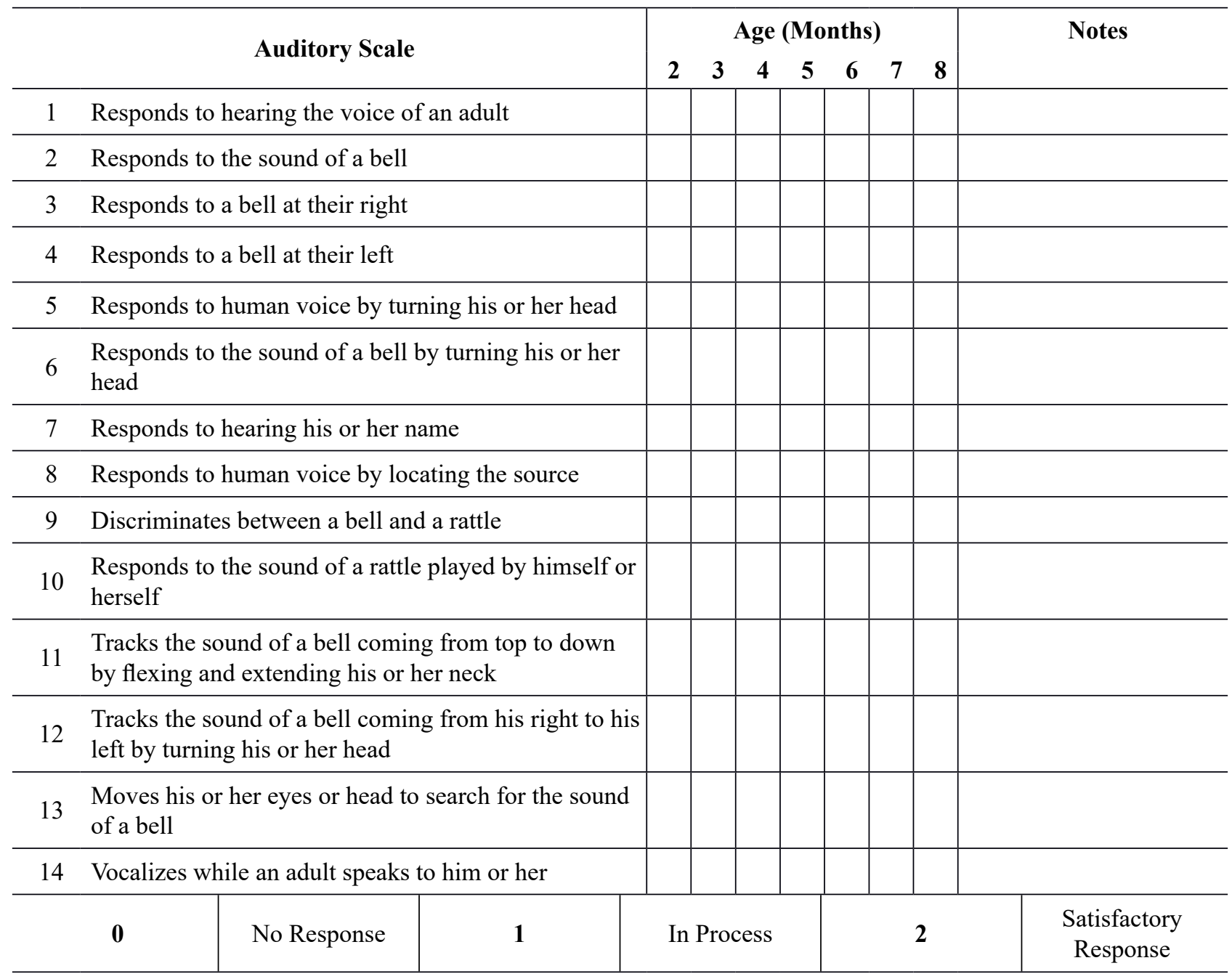

